\title{
Shelf Life of Crescenza Cheese as Measured by Electronic Nose
}

\author{
S. Benedetti, N. Sinelli, S. Buratti, and M. Riva \\ Department of Food Science and Technology, University of Milan, Italy
}

\begin{abstract}
The shelf life of Crescenza, a traditional Italian soft cheese, was measured using classical analysis and a commercial electronic nose. Two lots of samples directly supplied by a manufacturer at the beginning of their commercial life were stored at 2 constant temperatures ( 8 and $15^{\circ} \mathrm{C}$ ) and analyzed until their respective expiration dates. Among the physicochemical parameters, $\mathrm{pH}$, acidity, hue, and apparent yield rheological index appeared to be the best predictors of the quality decay. Changes in these indices were described with a sigmoidal transition function allowing definition of a loose and a severe shelf-life protocol, based on the trend of first and second time derivatives. A time range of 1 to $3 \mathrm{~d}$ at $15^{\circ} \mathrm{C}$ and 4 to $8 \mathrm{~d}$ at $8^{\circ} \mathrm{C}$ was accordingly assessed to maintain the freshness of Crescenza cheese. The quality decay of cheese aroma was evaluated by inspecting the headspace fingerprint of the same set of samples using the electronic nose. Sample classification through the aroma fingerprint confirmed the predicted shelf-life time ranges. A clear discrimination between "fresh," "aged," and "very aged" samples was obtained using principal components analysis, cluster analysis, and linear discriminant analysis statistical techniques. The predictive ability of the linear discriminant analysis classification model was confirmed by considering a new set of cheese samples purchased at the beginning of their commercial life from a local market and analyzed until their expiration date.
\end{abstract}

(Key words: shelf life, electronic nose, Crescenza cheese, headspace analysis)

Abbreviation key: CA = cluster analysis, $\mathbf{E N}=$ electronic nose, LDA = linear discriminant analysis, $\mathbf{P C A}=$ principal components analysis.

\section{INTRODUCTION}

The evaluation of the shelf life of perishable foods is a key area in the modern production and distribution.

Received April 1, 2005

Accepted June 1, 2005.

Corresponding author: Nicoletta Sinelli; e-mail: nicoletta.sinelli@ unimi.it.
The study of shelf life of fresh cheese using traditional and innovative methods is a useful tool to characterize the kinetics of the quality decay and to define an acceptability or stability time for their marketing and storage.

Crescenza cheese freshness is one of the most required attributes by the consumer and is strongly influenced by storage conditions. One of the main factors affecting the shelf life is a temperature abuse (Labuza, 1982; Singh, 1994). Fresh cheese is a living product, and its ripening continues throughout marketing, with a shift of chemical and sensory properties. An important commercial goal for soft and unripened cheeses is to maintain their freshness related to some specific sensory characteristics: white and brilliant color, creamy visual texture and spreadability, milky aroma and flavor, or low acidity. All these characteristics are slightly modified during the early progress of the lipolytic and proteolytic processes caused by the natural microflora.

Crescenza is a soft-ripened, rindless, cows' milk cheese made in the traditional Italian square shape and modeled after Italy's Stracchino. Crescenza is made from whole pasteurized cows' milk, heated to 37 to $39^{\circ} \mathrm{C}$, with added natural lactic ferment (Streptococcus thermophilus, acidity of 18 to $22^{\circ}$ Soxhlet Henkel), and liquid rennet. As soon as the curds are formed, they are cut into tiny pieces and left at rest in the appropriate molds to purge as much whey as possible. The cheese is then stewed at 23 to $28^{\circ} \mathrm{C}$ for 3 to $5 \mathrm{~h}$, salted, and left for 4 to $6 \mathrm{~d}$ before selling. After this period, the cheese is creamy, smooth, yeasty, and slightly tart. It is very thinly sliced and spread or melted on flatbread. Originally, Crescenza was produced exclusively during the winter months in the Lombardy region. Currently, it is manufactured on an industrial scale throughout the year. Crescenza freshness decays quickly ( 2 to $3 \mathrm{wk}$ even if wrapped well and stored at $4^{\circ} \mathrm{C}$ ) and should be consumed shortly after purchase.

Crescenza is white with a soft and creamy paste, a milky flavor, and a pasty texture (Rossi, 1982). After only a few days of storage (depending on temperature), the paste of the Crescenza cheese becomes yellow and often develops a sour taste. Crescenza freshness is generally associated with low acidity, limited proteolysis, and no bitter or sour taste. Crescenza is a fresh cheese in which structural and physicochemical modifications occur during storage due to enzymatic activities, par- 
tially related to microbial growth (Ghitti and Ottogalli, 1986). The severity of these modifications, as determined by measurements of structural and colorimetric variations of the cheese, and on the development of volatile compounds influencing sensory evaluation (Jou and Harper, 1998), depends on the storage and transport conditions.

Several studies have been carried out to monitor the shelf life of fresh cheeses using chemical and physicochemical indices (Lobato-Calleros and Aguirre-Mandujano, 2000; Toppino et al., 2002; Toppino and Riva, 2003). Some of these methods are time consuming and complex for routine quality control. Among the transformations that take place during the storage, visual modifications (color, shape, structure) and flavor changes are particularly important as they can influence the choice by consumer, resulting in prejudgment or "flavor anticipation" (Warburton, 2003). Image analysis and evaluation of the odor profile by means of an electronic nose (EN) are techniques that allow the objective and rapid measurement of parameters that can be easily correlated to the shelf life of the dairy products. The EN is a device equipped with an array of weakly specific and broad-spectrum chemical sensors that should mimic the human olfactory perception and provide a digital fingerprint of the odorant, which can be analyzed with appropriate statistical software. Such characteristics greatly facilitate the application of the EN to rapid monitoring of the volatile components of food, providing real-time information (Shaller et al., 1999). In the literature, there are several examples that demonstrate the use of an EN to study the shelf life of ricotta (Toppino et al., 2004) and Taleggio (Benedetti et al., 2002) cheeses or butter (Riva et al., 2004).

The aim of our study was to assess the suitability of the EN to define the shelf life of Crescenza cheese. The performance of the sensor arrays was compared with the results of classical analytical techniques, such as chemical and rheological analysis and color evaluation. The EN information was analyzed with pattern recognition techniques, including principal component analysis (PCA), cluster analysis (CA), and linear discriminant analysis (LDA).

\section{MATERIALS AND METHODS}

\section{Samples}

Two lots of Crescenza cheese packets ( $250 \mathrm{~g})$, directly supplied by a manufacturer at the beginning of their commercial life, were stored under constant temperature conditions at 8 and $15^{\circ} \mathrm{C}$ in the original paper packaging. Storage temperature was continuously monitored using a micro-recorder device (TB Econorma
SAS, Treviso, Italy). Samples stored at $8 \pm 1^{\circ} \mathrm{C}$ and at $15 \pm 1^{\circ} \mathrm{C}$ were analyzed every $3 \mathrm{~d}$ in a $31-\mathrm{d}$ period and every day for a 10-d period, respectively. For every sampling, 3 packets were opened and used to perform chemical and physicochemical, rheological, and EN analyses.

Furthermore, 14 Crescenza packets of the same brand and purchased from a local market at the beginning of their commercial life were used for the validation of the EN tests after $0,6,13$, and $20 \mathrm{~d}$ storage at 8 and $15^{\circ} \mathrm{C}$. All samples were kept at room temperature $\left(20 \pm 1^{\circ} \mathrm{C}\right)$ for $30 \mathrm{~min}$ before analysis. Each sample was evaluated in duplicate and the average of the results was used for statistical analysis.

\section{Chemical, Physicochemical, and Rheological Analyses}

Titratable acidity, $\mathrm{pH}$, and DM (International Dairy Federation, 1991) were determined in duplicate on each sample. The colorimetric parameter hue (the $\mathrm{a}^{*} / \mathrm{b}^{*}$ ratio) (Judd and Wyszecki, 1975) was determined inside the cheese using a CR-310 Minolta Meter colorimeter (Minolta Camera Co. Ltd., Osaka, Japan) and expressed as the average of 3 replicates.

Texture was analyzed using the vane test (Daubert et al., 1998). The test was performed with a viscometer (Viscotest VT 500, Mess Technik Gmg Hu. Co., Karlsruhe, Germany) and a 4-bladed vane rotor (model FL1000, Haake Mess-Technik GmbH, Karlsruhe, Germany). The vane ( $8.8 \mathrm{~mm}$ height, $5 \mathrm{~mm}$ radius, $1 \mathrm{~mm}$ thickness) was gently lowered into the sample and rotated at constant speed of $2 \mathrm{rpm}$ for $1 \mathrm{~min}$. The maximum vane stress $(\mathrm{Pa})$ corresponding to the yield stress $\left(\tau_{\max }\right)$, and the apparent yield ( $\left.\mathrm{rad}\right)$ were recorded (10 replicates).

\section{EN Apparatus}

Analyses were performed with an electronic nose (model 3320, Applied Sensor Laboratory Emission Analyser; Applied Sensor Co., Linkoping, Sweden), consisting of 3 parts: an automatic sampling apparatus, a detector unit containing the array of sensors, and software for pattern recognition. The automatic sampling system supported a carousel of 12 loading sites for the samples under controlled temperature. The sensor array included 22 different sensors, 10 of which were metal oxide semiconductor field effect transistors and 12 of which were Taguchi-type sensors (metal oxide semiconductors). The metal oxide semiconductor field effect transistors sensors were divided into 2 arrays of 5 sensors each, one array operating at $140^{\circ} \mathrm{C}$ and the other at $170^{\circ} \mathrm{C}$, whereas the metal oxide semiconductor 
sensors, mounted in a separate chamber, were kept at 400 to $500^{\circ} \mathrm{C}$ during all the process phases (Shaller et al., 1998).

Two grams of each sample was placed in a $40-\mathrm{mL}$ Pyrex vial with a silicone cap and placed into the automatic sampling carousel. Preliminary trials indicated that larger sample volumes did not significantly enhance signal intensity and reproducibility. After a $20-$ min equilibration at room temperature $\left(20 \pm 1^{\circ} \mathrm{C}\right)$, the measurement run started with a 10-min incubation at $25^{\circ} \mathrm{C}$. Airflow (room air filtered through active carbon) was conveyed over the sensors at a constant rate (1 $\mathrm{cm}^{3} / \mathrm{s}$ ) for $10 \mathrm{~s}$ to stabilize the baseline. An automatic syringe then aspirated the Crescenza cheese headspace and conveyed it over the sensor surfaces for $30 \mathrm{~s}$. The sensors were exposed again to the reference airflow to eventually recover the baseline. The total cycle time for each measurement was 5 min. No sensor drift during the measurement period was experienced. Each sample was evaluated 3 times and the average of the results was used for the analysis.

\section{Data Analyses}

The chemical, physicochemical, and rheological data were evaluated through simple mathematical models with Tablecurve 2D software v. 4.0 (Jandel Scientific, San Rafael, CA) to assess the raw trend of each index.

The data obtained from the sensor array of the electronic nose were analyzed by PCA, CA, and LDA performed with SCAN software (Minitab Inc., State College, PA).

Principal components analysis is used for explorative data analysis as it identifies orthogonal directions of maximum variance in the original data, in decreasing order, and projects the data into a lower-dimensionality space formed of subset of the highest-variance components. The orthogonal directions are linear combinations (principal components) of the original variables and each component explains, in turn, a part of the total variance of the data; in particular, the first significant component explains the largest percentage of the total variance, the second one, the second largest percentage, and so on (Beebe et al., 1998).

Cluster analysis performs agglomerative hierarchical clustering of objects based on distance measures of dissimilarity or similarity. The hierarchy of clusters can be represented by a binary tree, or dendrogram. A final partition, the cluster assignment of each object, is obtained by cutting the tree at a specified level (Gardner and Bartlett, 1992).

Linear discriminant analysis is one of the most widely used parametric classification procedures. The method maximizes the variance between categories and mini- mizes the variance within categories. This method renders a number of orthogonal linear discriminant functions equal to the number of categories minus one (Meloun et al., 1992).

\section{RESULTS AND DISCUSSION}

\section{Chemical, Physicochemical, and Rheological Analyses}

Tables 1 and 2 show the trend of chemical, physicochemical, and rheological indices during the storage of the Crescenza cheese samples at 8 and $15^{\circ} \mathrm{C}$. Differences among the values of the fresh (time 0 ) samples can be associated with the variability of lots. The DM content showed a little variation among single packets and seemed to have no relationship with storage time due to the large heterogeneity of the samples. The real DM content is difficult to assess, as Crescenza is a fresh, creamy, and wet cheese with a noticeable drip phenomenon at the opening of the packet. For this reason, the DM behavior was not a reliable parameter and was not able to correctly describe modifications strictly related to the shelf-life period. For the 2 storage temperatures considered, a decrease of $\mathrm{pH}$ values was observed at the end of storage and seemed highly correlated with titratable acidity. In fact, cheese samples showed an increase of the acidity values during the storage at both temperatures, although the samples stored at $8^{\circ} \mathrm{C}$ showed a stable value $(0.9 \mathrm{~g}$ of lactic acid/100 $\mathrm{g}$ of cheese) from d 20 until the end of the storage. This time $(20 \mathrm{~d})$ corresponds to the labeled expiration date. The same trend was observed for the samples stored at $15^{\circ} \mathrm{C}$, although with different acidity, attributed to the variability of the lots. In the cheese paste, a decrease of hue values (from -0.193 to -0.220 for cheese stored at $8^{\circ} \mathrm{C}$ and from -0.183 to -0.231 for cheese stored at $15^{\circ} \mathrm{C}$ ) could be associated with a tendency of yellowing, probably due to the oxidation and lipolytic phenomena. The hue index is the ratio of 2 color parameters: red ( $\left.a^{*}\right)$, a variation of the color from green to red, and blue $\left(b^{*}\right)$, a shift from blue to yellow (Judd and Wyszecki, 1975). The $\Delta$ hue values $\left(\right.$ hue $_{\mathrm{t}}-\mathrm{hue}_{0}$ ) increased between $\mathrm{d} 9$ and 13 during storage at $8^{\circ} \mathrm{C}$, whereas the shift was already noticeable in the first phase ( $\mathrm{d} 0$ to 7 ) of storage at $15^{\circ} \mathrm{C}$. Trends of the rheological parameters, namely yield stress $\left(\tau_{\max }\right)$ and apparent yield (rad), during storage at $8^{\circ} \mathrm{C}$ highlighted a progressive increase of paste hardness: the $\tau_{\max }$ increased up to a constant value of about $2100 \mathrm{~Pa}$ and the apparent yield decreased after d 20 of storage (the expiration date). On the contrary, at $15^{\circ} \mathrm{C}$, there was great variability of the $\tau_{\max }$ data, probably due to the structure of the cheese, which col- 
Table 1. Chemical and physicochemical indices (mean \pm SD) of Crescenza cheese samples monitored during storage at $8^{\circ} \mathrm{C}$.

\begin{tabular}{|c|c|c|c|c|c|c|c|c|}
\hline $\begin{array}{l}\text { Time, } \\
\text { d }\end{array}$ & $\begin{array}{l}\text { DM, } \\
\text { g/100 g }\end{array}$ & $\mathrm{pH}$ & $\begin{array}{l}\text { Titratable } \\
\text { acidity, } \\
\mathrm{g} \text { of lactic } \\
\text { acid/ } 100 \mathrm{~g} \\
\text { of cheese }\end{array}$ & $\begin{array}{l}\text { Redness } \\
\left(\mathrm{a}^{*}\right)\end{array}$ & $\begin{array}{l}\text { Blueness } \\
\left(b^{*}\right)\end{array}$ & $\begin{array}{l}\text { Hue } \\
\left(\mathrm{a}^{*} / \mathrm{b}^{*}\right)\end{array}$ & $\tau_{\max }, \mathrm{Pa}$ & $\begin{array}{l}\text { Apparent } \\
\text { yield, rad }\end{array}$ \\
\hline 0 & $39.60 \pm 0.95$ & $5.26 \pm 0.034$ & $0.674 \pm 0.030$ & $-3.04 \pm 0.065$ & $15.75 \pm 0.28$ & -0.193 & $1792.6 \pm 410.2$ & $1.29 \pm 0.11$ \\
\hline 3 & $38.84 \pm 0.23$ & $5.37 \pm 0.036$ & $0.688 \pm 0.003$ & $-3.31 \pm 0.590$ & $16.60 \pm 0.27$ & -0.200 & $1784.4 \pm 300.7$ & $1.40 \pm 0.12$ \\
\hline 7 & $40.89 \pm 0.61$ & $5.18 \pm 0.065$ & $0.709 \pm 0.049$ & $-3.86 \pm 0.049$ & $18.30 \pm 0.36$ & -0.211 & $2024.1 \pm 402.7$ & $1.14 \pm 0.12$ \\
\hline 17 & $39.74 \pm 0.17$ & $5.04 \pm 0.022$ & $0.833 \pm 0.016$ & $-4.09 \pm 0.053$ & $18.63 \pm 0.36$ & -0.220 & $2148.6 \pm 579.7$ & $0.82 \pm 0.17$ \\
\hline 20 & $40.50 \pm 0.52$ & $5.08 \pm 0.056$ & $0.887 \pm 0.020$ & $-4.18 \pm 0.084$ & $19.28 \pm 0.40$ & -0.217 & $2127.3 \pm 597.9$ & $0.75 \pm 0.18$ \\
\hline 22 & $40.92 \pm 0.51$ & $5.07 \pm 0.028$ & $0.909 \pm 0.025$ & $-4.05 \pm 0.150$ & $18.94 \pm 0.60$ & -0.213 & $2296.6 \pm 560.7$ & $0.84 \pm 0.11$ \\
\hline 27 & $42.42 \pm 0.16$ & $4.99 \pm 0.04$ & $0.897 \pm 0.036$ & $-4.25 \pm 0.079$ & $20.12 \pm 0.34$ & -0.211 & $2366.8 \pm 718.7$ & $0.87 \pm 0.22$ \\
\hline 31 & $40.92 \pm 0.47$ & $4.90 \pm 0.053$ & $0.901 \pm 0.011$ & $-4.19 \pm 0.059$ & $19.04 \pm 0.30$ & -0.220 & $2284.1 \pm 222.4$ & $0.79 \pm 0.10$ \\
\hline
\end{tabular}

${ }^{1} \mathrm{ND}=$ Not determined.

lapsed and become more fluid. Therefore, the apparent yield values decreased to a constant value after $d 6$ indicating a progressive increase of hardness during storage.

A simple and raw mathematical model (a sigmoidal transition function) was applied to describe the evolution of some chemical, physicochemical, and rheological parameters during storage. The data were fitted using the equation:

$$
\mathrm{y}=\mathrm{a}+\mathrm{b} /[1+\exp (-(\mathrm{t}-\mathrm{c}) / \mathrm{d})]
$$

where $\mathrm{a}$ is the maximum shift (from initial to equilibrium value) of the considered index (y), $b$ is the transition center, $\mathrm{t}$ is the time, and $\mathrm{c}$ and $\mathrm{d}$ are 2 constants. The use of this type of sigmoidal function is justified by the nature (enzymatic or microbial-induced) of the transformations in progress. The first and second derivatives of the transition function were calculated to measure the time related to the maximum rate and acceleration of the process. The maximum of the first and second time derivative correspond to a loose and a se- vere definition of shelf life, respectively (Riva et al., 2001; Toppino and Riva, 2003). An example of the evolution of titratable acidity at $8^{\circ} \mathrm{C}$ is shown in Figure 1 . As can be seen, the experimental data are well fitted by the sigmoidal function.

Table 3 reports the stability times (loose and severe definitions of shelf life) based on the titratable acidity, $\mathrm{pH}$, hue, apparent yield, and their averages. These times are all calculated with the same sigmoidal parameterization, with reference to storage at 8 and $15^{\circ} \mathrm{C}$. As can be seen in Table 3, the phenomena of the quality decay or shelf-life expiration depend on the storage temperature: stability times (according to the 2 definitions) are 1 to $3 \mathrm{~d}$ at $15^{\circ} \mathrm{C}$, and 4 to $8 \mathrm{~d}$ at $8^{\circ} \mathrm{C}$. Based on the severe criterion (which is more reliable for shelf-life dating), the Crescenza cheese shows an important chemical and structural modification after $1 \mathrm{~d}$ of storage at $15^{\circ} \mathrm{C}$ and after $4 \mathrm{~d}$ at $8^{\circ} \mathrm{C}$. Influence of temperature can be expressed by a $Q_{10}$ value (a number-fold decrease of stability time for an increase of $10^{\circ} \mathrm{C}$ of storage temperature) of about 3 to 4 . This interval corresponds to a moderate effect of temperature, which is adequate

Table 2. Chemical and physicochemical indices (mean \pm SD) of Crescenza cheese samples monitored during storage at $15^{\circ} \mathrm{C}$.

\begin{tabular}{|c|c|c|c|c|c|c|c|c|}
\hline $\begin{array}{l}\text { Time, } \\
\mathrm{d}\end{array}$ & $\begin{array}{l}\text { DM, } \\
\text { g/100 g }\end{array}$ & $\mathrm{pH}$ & $\begin{array}{l}\text { Titratable } \\
\text { acidity, } \\
\mathrm{g} \text { of lactic } \\
\text { acid/100 g } \\
\text { of cheese }\end{array}$ & $\begin{array}{l}\text { Redness } \\
\left(\mathrm{a}^{*}\right)\end{array}$ & $\begin{array}{l}\text { Blueness } \\
\left(\mathrm{b}^{*}\right)\end{array}$ & $\begin{array}{l}\text { Hue } \\
\left(\mathrm{a}^{*} / \mathrm{b}^{*}\right)\end{array}$ & $\tau_{\max }, \mathrm{Pa}$ & $\begin{array}{l}\text { Apparent } \\
\text { yield, rad }\end{array}$ \\
\hline 0 & $39.37 \pm 0.26$ & $5.40 \pm 0.071$ & $0.904 \pm 0.021$ & $-3.06 \pm 0.037$ & $16.72 \pm 0.18$ & -0.183 & $2036.5 \pm 662.6$ & $1.37 \pm 0.34$ \\
\hline 3 & $42.52 \pm 0.55$ & $5.07 \pm 0.047$ & $0.983 \pm 0.057$ & $-3.79 \pm 0.054$ & $16.97 \pm 0.23$ & -0.223 & $1351.3 \pm 490.9$ & $1.12 \pm 0.35$ \\
\hline 4 & $39.69 \pm 0.11$ & $5.12 \pm 0.042$ & $1.215 \pm 0.068$ & $-2.25 \pm 0.073$ & $5.79 \pm 0.43$ & -0.388 & $1367.3 \pm 350.2$ & $0.85 \pm 0.28$ \\
\hline 7 & $38.51 \pm 0.04$ & $4.86 \pm 0.033$ & $1.466 \pm 0.049$ & $-4.13 \pm 0.018$ & $18.06 \pm 0.12$ & -0.228 & $1598.9 \pm 296.9$ & $0.80 \pm 0.27$ \\
\hline 10 & $44.88 \pm 0.08$ & $4.79 \pm 0.024$ & $1.459 \pm 0.018$ & $-4.01 \pm 0.063$ & $17.35 \pm 0.52$ & -0.231 & $2453.3 \pm 776.8$ & $0.84 \pm 0.25$ \\
\hline
\end{tabular}




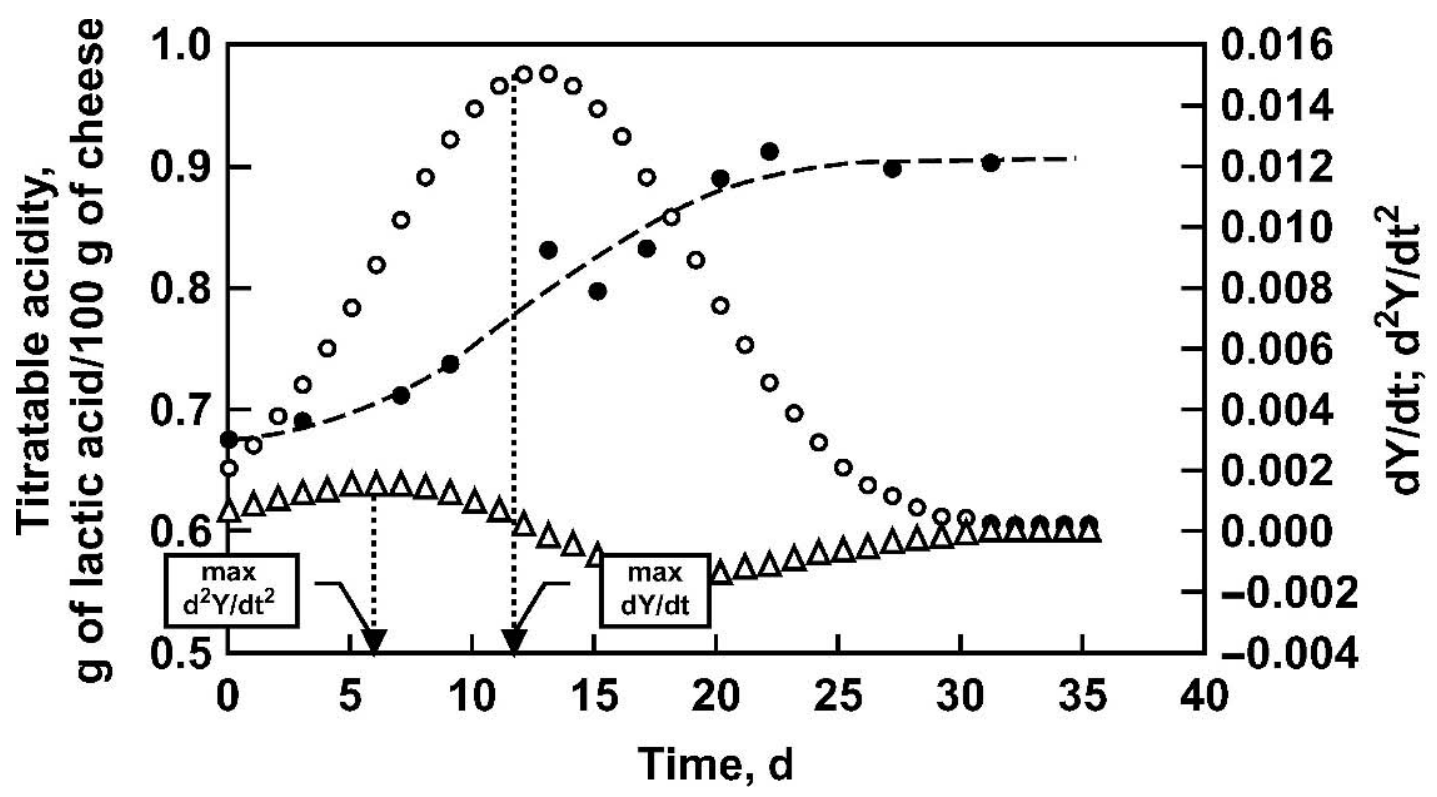

Figure 1. Evolution of titratable acidity ( $\mathrm{g}$ of lactic acid/100 $\mathrm{g}$ of cheese) at $8^{\circ} \mathrm{C}$. A transition function (dashed line, --- ) was used to fit the experimental data. The first time derivative maximum (maximum speed of decay process, dY/dt) and the second time derivative maximum ( $\max$ acceleration of decay process, $\left.\mathrm{d}^{2} \mathrm{Y} / \mathrm{dt}^{2}\right)$ were evaluated; $(\bullet)$ experimental data, $(\bigcirc)$ first derivative, and $(\Delta)$ second derivative.

for fresh foods whose quality is primarily affected by enzymatic or microbial activity (Labuza, 1982).

\section{Electronic Nose}

The EN was used to evaluate the headspace of Crescenza cheese stored at 8 and $15^{\circ} \mathrm{C}$. The sensor responses were collected and elaborated by PCA performed on scaled data to achieve a partial visualization of the set in a reduced dimension. The first 2 principal components represented $98 \%$ of the total variance, and their score plot (Figure 2) allowed separation of the samples according to the storage conditions. Samples were distributed along PC1 and PC2 according to the storage time and storage temperature, respectively.

To identify some groups among Crescenza cheese samples, the hierarchical CA was applied to EN sensor responses. Figure 3 shows the dendrogram obtained using the Ward method and the square Euclidian distance. As can be seen, at a dissimilarity distance of about 5,3 groups of samples can be identified and classified as follow: fresh, corresponding to 0 to $7 \mathrm{~d}$ at $8^{\circ} \mathrm{C}$ and 0 to $4 \mathrm{~d}$ at $15^{\circ} \mathrm{C}$; aged, relating to 9 to $20 \mathrm{~d}$ at $8^{\circ} \mathrm{C}$ and 5 to $7 \mathrm{~d}$ at $15^{\circ} \mathrm{C}$; and very aged, for samples from 22 to $31 \mathrm{~d}$ at $8^{\circ} \mathrm{C}$ and after $10 \mathrm{~d}$ at $15^{\circ} \mathrm{C}$.

To characterize Crescenza cheese samples into the fresh, aged, and very aged classes, a supervised pattern recognition method was applied. In Table 4, the results of LDA and leave-one-out cross-validation are reported. Linear discriminant analysis applied to the sensor responses gave $100 \%$ recognition for all Crescenza cheese (error rate $0 \%$ ), and leave-one-out cross-validation classified all samples correctly (cross-validation error rate $0 \%$ ). Figure 4 showed how the first 2 LDA functions

Table 3. Time related to loose $\left(\max \mathrm{d}^{2} \mathrm{y} / \mathrm{dt}^{2}\right)$ and severe (max dy/dt) criteria of shelf life of some chemical and physicochemical indices of Crescenza cheese stored at 8 and $15^{\circ} \mathrm{C}$.

\begin{tabular}{|c|c|c|c|c|c|c|c|c|c|c|}
\hline \multirow[b]{2}{*}{ Temperature, ${ }^{\circ} \mathrm{C}$} & \multicolumn{2}{|c|}{$\mathrm{pH}$} & \multicolumn{2}{|c|}{$\begin{array}{l}\text { Titratable acidity, } \\
\text { g of lactic acid/ } \\
100 \mathrm{~g} \text { of cheese }\end{array}$} & \multicolumn{2}{|c|}{ Hue $\left(a^{*} / b^{*}\right)$} & \multicolumn{2}{|c|}{$\begin{array}{l}\text { Apparent yield, } \\
\operatorname{rad}\end{array}$} & \multicolumn{2}{|c|}{ Average } \\
\hline & $\begin{array}{l}\operatorname{Max} \\
d^{2} y / d^{2}\end{array}$ & $\begin{array}{l}\operatorname{Max} \\
\mathrm{dy} / \mathrm{dt}\end{array}$ & $\begin{array}{l}\text { Max } \\
d^{2} y / d t^{2}\end{array}$ & $\begin{array}{l}\operatorname{Max} \\
\mathrm{dy} / \mathrm{dt}\end{array}$ & $\begin{array}{l}\text { Max } \\
d^{2} y / d t^{2}\end{array}$ & $\begin{array}{l}\text { Max } \\
\text { dy/dt }\end{array}$ & $\begin{array}{l}\operatorname{Max} \\
\mathrm{d}^{2} \mathrm{y} / \mathrm{dt}^{2}\end{array}$ & $\begin{array}{l}\operatorname{Max} \\
\mathrm{dy} / \mathrm{dt}\end{array}$ & $\begin{array}{l}\text { Max } \\
d^{2} y / d t^{2}\end{array}$ & $\begin{array}{l}\text { Max } \\
\mathrm{dy} / \mathrm{dt}\end{array}$ \\
\hline 8 & 3.5 & 6.8 & 5.9 & 12.8 & 1.1 & 4.8 & 6.2 & 7.5 & 4.2 & 8.0 \\
\hline 15 & 0.3 & 2.6 & 2.1 & 3.8 & 0.5 & 3.0 & 2.6 & 3.1 & 1.4 & 3.1 \\
\hline
\end{tabular}




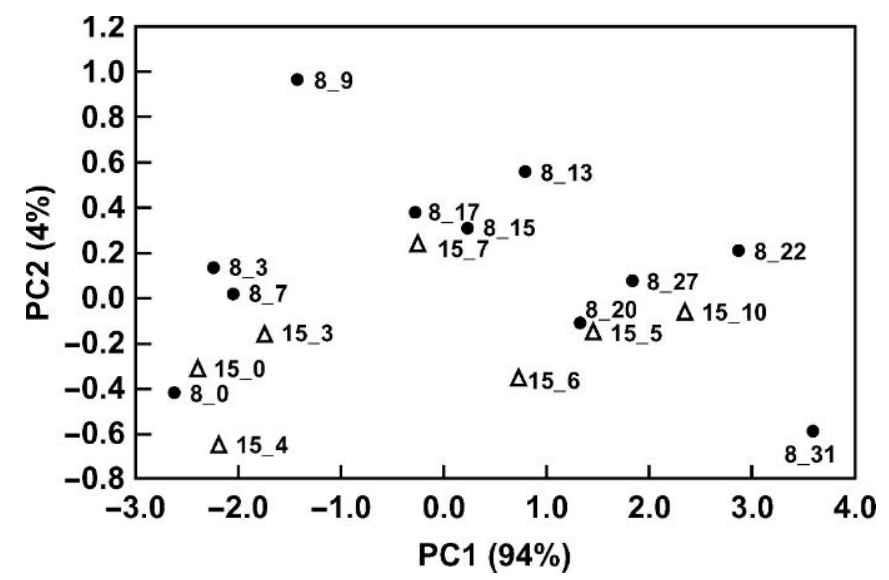

Figure 2. Principal components analysis score plot of Crescenza cheese samples in the plane defined by the first 2 principal components; $(\bullet)$ samples stored at $8^{\circ} \mathrm{C}$ and $(\Delta)$ samples stored at $15^{\circ} \mathrm{C}$.

discriminated among classes. Function 1 seemed to discriminate mostly fresh from aged and very aged samples. In the vertical direction (function 2), there was an evident discrimination between aged and very aged cheese samples. These classification techniques seem able to differentiate the storage time at the 2 temperatures considered. The LDA applied to EN data was particularly useful to classify the 3 groups of Crescenza cheese samples and to identify a threshold for maintaining freshness at each temperature.

The classification model was applied to a new set of EN data; that is, the 7 Crescenza packets purchased from a local market and analyzed at the beginning of the storage and after 6,13 , and $20 \mathrm{~d}$ at 8 and $15^{\circ} \mathrm{C}$. Figure 5 shows the predictive ability of LDA model. It can be seen that 3 samples stored at 0 and $6 \mathrm{~d}$ at 8 and $15^{\circ} \mathrm{C}$, respectively were grouped in the fresh class,
Square Euclidian Distance

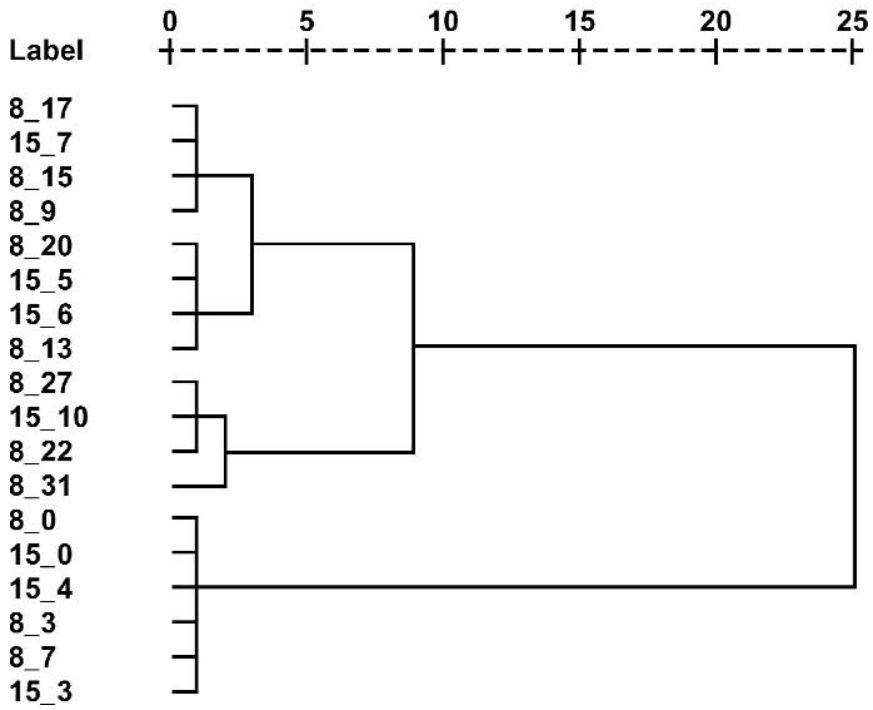

Figure 3. Classification dendrogram (cluster analysis) of Crescenza cheese samples stored at 8 and $15^{\circ} \mathrm{C}$ (label indicates temperature and storage time in d).

whereas 4 samples stored for 13 and $20 \mathrm{~d}$ at 8 and $15^{\circ} \mathrm{C}$, respectively, were classified as aged cheese.

When comparing stability times (loose criterion) of physicochemical parameterization with the EN results, an agreement between maintenance of freshness thresholds was found. This result is a further confirmation of EN suitability in the dairy industry; previous studies on other fresh cheeses or dairy products, such as ricotta (Toppino et al., 2004), Taleggio (Benedetti et al., 2002), or butter (Riva et al., 2004) reached the same conclusions about the correlation between physicochemical and sensorial parameterization of shelf life.

Table 4. Classification of Crescenza cheese samples by linear discriminant analysis.

\begin{tabular}{|c|c|c|c|c|c|}
\hline & \multirow[b]{2}{*}{ Class } & \multicolumn{3}{|c|}{ Predicted group } & \multirow[b]{2}{*}{ Total } \\
\hline & & Fresh & Aged & Very aged & \\
\hline \multicolumn{6}{|l|}{ Original } \\
\hline \multirow[t]{3}{*}{ Count } & Fresh & 6 & 0 & 0 & 6 \\
\hline & Aged & 0 & 8 & 0 & 8 \\
\hline & Very aged & 0 & 0 & 4 & 4 \\
\hline \multirow[t]{3}{*}{$\%$} & Fresh & 100.0 & 0.0 & 0.0 & 100.0 \\
\hline & Aged & 0.0 & 100.0 & 0.0 & 100.0 \\
\hline & Very aged & 0.0 & 0.0 & 100.0 & 100.0 \\
\hline \multicolumn{6}{|c|}{ Cross-validated } \\
\hline \multirow[t]{3}{*}{ Count } & Fresh & 6 & 0 & 0 & 6 \\
\hline & Aged & 0 & 8 & 0 & 8 \\
\hline & Very aged & 0 & 0 & 4 & 4 \\
\hline \multirow[t]{3}{*}{$\%$} & Fresh & 100.0 & 0.0 & 0.0 & 100.0 \\
\hline & Aged & 0.0 & 100.0 & 0.0 & 100.0 \\
\hline & Very aged & 0.0 & 0.0 & 100.0 & 100.0 \\
\hline
\end{tabular}




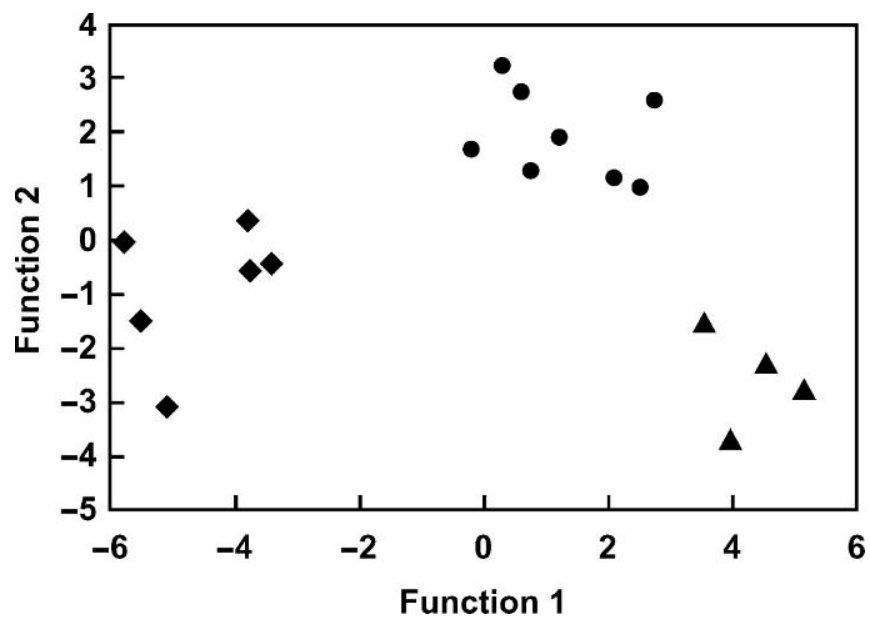

Figure 4. Projections of Crescenza cheese samples in the space defined by the linear discriminant analysis discriminant functions 1 and $2 ;(\bullet)$ fresh samples, $(\bullet)$ aged samples, and $(\boldsymbol{\Delta})$ very aged samples.

\section{CONCLUSIONS}

Shelf-life studies require a fast and pragmatic approach in practice: when safety is assured, only the sensory quality decay can be monitored and parameterized. In this perspective, as demonstrated in this work, the electronic nose can help to analyze the complex evolution of the aroma profile. Given its nonspecific nature, the EN headspace sensor arrays can perform

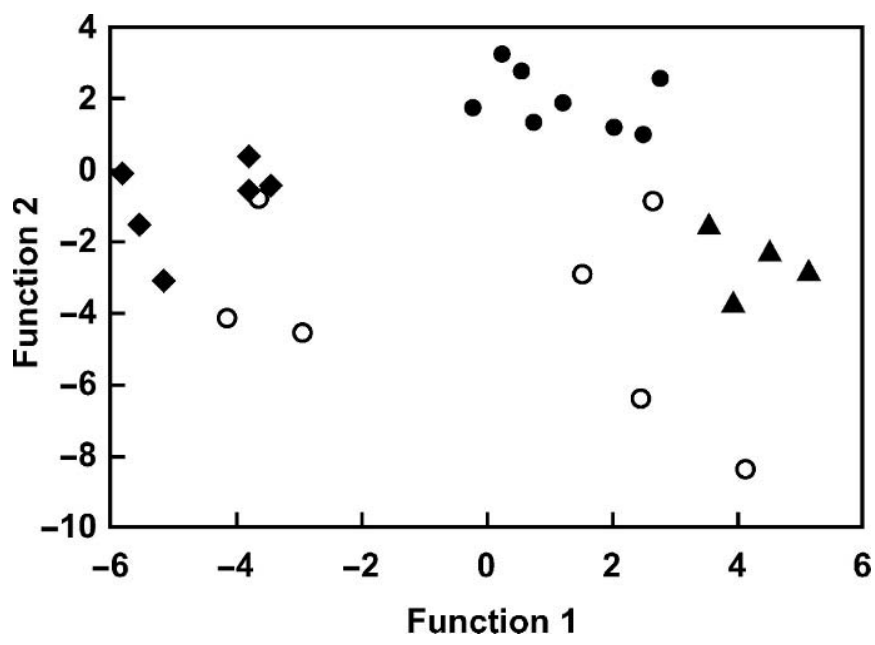

Figure 5. Projection of Crescenza cheese samples and new Crescenza cheese samples predicted by the linear discriminant analysis

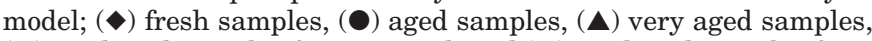
(○) predicted samples from 0 to $6 \mathrm{~d}$, and $(\square)$ predicted samples from 13 to $20 \mathrm{~d}$. only "yes or no" tests inside the set of products. Contrary to traditional analytical methods, the EN sensor responses do not need and do not provide information on the nature of the compounds under investigation, but only its digital fingerprint. The change in this fingerprint during storage is a useful criterion to define or confirm the hypothesis of shelf life dating. From the results illustrated in this study, it is clear that the sensor responses of the electronic nose can be used to define the threshold of the shelf life of Crescenza samples stored at different temperatures. Linear discriminant analysis is an important technique to create a model able to classify fresh, aged, and very aged samples, and to predict the aroma-based shelf life of a new set of cheese samples. Other classical analytical indices related to sensory decay (e.g., acidity, color, and texture in Crescenza cheese) can support this pragmatic approach. This study demonstrated that the shelf life ranges obtained by the electronic nose and traditional analytical techniques are substantially similar.

\section{REFERENCES}

Beebe, K. R., R. J. Pell, and M. B. Seasholtz. 1998. Chemometrics, a practical guide. John Wiley and Sons, New York, NY.

Benedetti, S., P. M. Toppino, and M. Riva. 2002. Studio della shelf life del formaggio Taleggio confezionato. 2. Applicazione di un naso elettronico. Sci. Tecn. Latt. Cas. 53:259-282.

Daubert, C. R., J. A. Tkachuk, and V. D. Truong. 1998. Quantitative measurement of food spreadability using the vane method. J. Texture Stud. 29:427-435.

Gardner, J. W., and P. N. Bartlett. 1992. Pattern recognition in odor sensing. Pages 161-179 in Sensors and Sensory systems for an Electronic Nose. J. W. Gardner and P. N. Bartlett, ed. Dordrecht Kluwer Academic Publishers, Boston, MA.

Ghitti, C., and G. Ottogalli. 1986. Il formaggio Crescenza. Sci. Tecn. Latt. Cas. 37:495-506.

International Dairy Federation. 1991. Dry matter determination. Provisional Standard 151:1991. FIL-IDF, International Dairy Federation, Brussels, Belgium.

Jou, K. D., and W. J. Harper. 1998. Pattern recognition of Swiss cheese aroma compounds by SPME/GC and an electronic nose. Milchwissenschaft 53:259-263.

Judd, D. B., and G. Wyszecki. 1975. Color in Business, Science and Industry. John Wiley and Sons, New York, NY.

Labuza, T. P. 1982. Scientific evaluation of shelf life. Pages 41-44 in Shelf-Life Dating of Foods. T. P. Labuza, ed. Food \& Nutrition Press Inc., Westport, CT.

Lobato-Calleros, C., and E. Aguirre-Mandujano. 2000. Viscoelastic properties of white fresh cheese filled with sodium caseinate. J. Texture Stud. 31:379-390.

Meloun, M., J. Militky, and M. Forina. 1992. Chemometrics for analytical chemistry. Ellis Horwood, New York, NY.

Riva, M., S. Benedetti, and N. Sinelli. 2004. Tecniche combinate NIRS e naso elettronico per lo studio della shelf life di prodotti lattierocaseari. Ingredienti Alimentari III:19-24.

Riva, M., D. Fessas, and A. Schiraldi. 2001. Isothermal calorimetry approach to evaluate shelf life of foods. Thermochim. Acta 6517:73-81.

Rossi, G. 1982. Crescenza. Pages 195-198 in Manuale di Tecnologia Casearia. G. Rossi, ed. Agricole, Bologna, Italy.

Shaller, E., J. O. Bosset, and F. Escher. 1998. Electronic noses and their application to food. Lebensm. Wiss. Technol. 31:305-316. 
Shaller, E., J. O. Bosset, and F. Escher. 1999. Practical experience with the "electronic nose" systems for monitoring the quality of dairy products. Chimia (Aarau) 53:98-102

Singh, R. P. 1994. Scientific principles of shelf life evaluation. Pages 3-26 in Shelf-Life Evaluation of Foods. C. M. D. Man and A. A. Jones, ed. Blackie Acad. Prof, London, UK.

Toppino, P. M., L. Campagnol, D. Carminati, G. Mucchetti, M. Povolo, S. Benedetti, and M. Riva. 2004. Shelf life study of packed industrial ricotta cheese. Ital. J. Food Sci. Special Issue:252-265.
Toppino, P. M., and M. Riva. 2003. Studio della predizione della shelf life dei formaggi. Sci. Tecn. Latt. Cas. 54:237-265.

Toppino, P. M., M. Riva, A. Cigoli, and G. Civardi. 2002. Studio della shelf-life del formaggio Taleggio confezionato. 1. Valutazione convenzionale e monitoraggio mediante un dispositivo TTI. Sci. Tecn. Latt. Cas. 53:81-106.

Warburton, D. 2003. The pleasure process. Food Sci. Technol. $17: 36-37$. 